\title{
COMMENTARY
}

\section{Bending the cost curve in the United States: the role of comparative effectiveness research}

\author{
Amir A Ghaferi* \\ See related research by Opmeer et al., http://ccforum.com/content/14/3/R97
}

\begin{abstract}
Owing to an increasing focus on the rising cost of medical care in the United States, bending the cost curve has become the central tenet of healthcare reform. The exact definition of this phrase, however, remains elusive. In order to affect change in the cost and quality of healthcare, the importance of comparative effectiveness research must be recognized.
\end{abstract}

In the current issue of Critical Care, Opmeer and colleagues present an economic follow-up to their randomized clinical trial regarding on-demand versus planned relaparotomies for severe peritonitis [1]. In light of recent feverish debates surrounding healthcare reform in the United States, bending the cost curve has become a slogan with increasing popularity. Numerous health policy institutes have written briefs, many special editions of health services journals have been published, and multiple editorials in the US media have been put forth trying to explain what this phrase entails, and of course the solution. What does bending the cost curve mean, however, and how can we achieve it (or even begin to achieve it)?

Inevitably, both healthcare professionals and patients wish to achieve optimal patient outcomes within a system bound by limited resources. While we have always recognized the need for optimal outcomes, we are only now coming to grips with the limited resources. Many continue to debate what the etiology of our high healthcare expenditures is; however, it is plainly obvious to some that a boom in technology and a heightened practice of defensive medicine have no doubt contributed. To rein in spending, therefore, we will require better knowledge about the effectiveness of existing and

*Correspondence: aghaferi@umich.edu

University of Michigan, Department of Surgery, 2207 Taubman Center, 1500 E. Medical Center Drive, Ann Arbor, Michigan 48109-0432, USA emerging diagnostic and treatment modalities, along with an appropriate system of accountability.

Although many nations have already recognized the importance of such research [2,3], the United States has only recently begun to embrace these goals with what it calls comparative effectiveness research. In 2009 the US Congress passed legislation (the American Recovery and Reinvestment Act) with $\$ 1.1$ billion in research funds targeting comparative effectiveness research. The US Institute of Medicine, at the behest of the US Congress, then created a priority list of comparative effectiveness research topics. To serve as a guide for their discussions, the Institute of Medicine described comparative effectiveness research as the generation and synthesis of evidence that compares the benefits and harms of alternative methods to prevent, diagnose, treat, and monitor a clinical condition, or to improve the delivery of care. The purpose of comparative effectiveness research is to assist consumers, clinicians, purchasers, and policy makers to make informed decisions that will improve health care at both the individual and population levels' [4].

To that end, Opmeer and colleagues present a study that is ahead of the curve [1]. They provide an excellent economic follow-up to their randomized clinical trial evaluating on-demand versus planned relaparotomy in patients with severe peritonitis [5]. Their initial study found no significant differences in morbidity or mortality in the on-demand relaparotomy group as compared with the planned relaparotomy group. There was, however, a substantial reduction in the number of relaparotomies, in healthcare utilization, and in direct medical costs. Moreover, the authors have taken their economic analysis one step further and now, using the societal perspective, provide a more in-depth evaluation of the costs associated with these two relaparotomy strategies. The authors examined direct medical costs (that is, hospital/intensive care unit admissions, therapeutic and diagnostic interventions, medications, and so forth), direct nonmedical costs (that is, travel to and from healthcare providers), and indirect costs (that is, loss of productivity due to impaired ability to work). They found substantially lower resource utilization in the on-demand group, 
making the argument for on-demand relaparotomies in patients with severe peritonitis even more convincing.

Unfortunately, this intriguing and very compelling analysis of a severely ill patient population raises more questions than it answers. New knowledge regarding the treatment strategies employed for many decades cannot affect significant change in practice patterns overnight. Such studies should, however, serve as a reminder to physicians choosing between treatments that there may be other equally efficacious, yet more cost-effective, options. Additionally, physicians should understand the economic impact of such decisions. Sadly, to what extent they use this economic information to bend their own cost curve is where frivolous arguments about death panels have arisen. Fortunately, such scare tactics are falling by the wayside and meaningful discussions about accountable care organizations and patient-centered medical homes are emerging [6]. These concepts rest on the notion that, in order to begin bending the cost curve, hospital and physician behaviors must be affected. The most prudent strategy to achieve this is through monetary incentives, where accountable care organizations and medical homes could serve as the lever for accountability, both financial and in the quality of care delivered. Research, such as Opmeer and colleagues' study, can serve to further inform the nuts and bolts of such programs, while providing invaluable information to physicians on the frontline of medicine.

\section{Competing interests}

The author declares that he has no competing interests.

Published: 22 June 2010

\section{References}

1. Opmeer BC, Boer KR, van Ruler O, Reitsma JB, Gooszen HG, de Graaf PW, Lamme B, Gerhards MF, Steller EP, Mahler CM, Obertop H, Gouma DJ, Bossuyt PM, de Borgie CA, Boermeester MA: Costs of relaparotomy on-demand versus planned relaparotomy in patients with severe peritonitis: an economic evaluation within a randomized controlled trial. Crit Care 2010, 14:R97.

2. Moynihan R, Oxman AD, Lavis JN, Paulsen E: Evidence-informed Health Policy: Using Research to Make Health Systems Healthier. Rapport Nr 1-2008. Oslo: Nasjonalt kunnskapssenter for helsetjenesten; 2008.

3. UK Department of Health: Best Research for Best Health: A New National Health Research Strategy. Report 272605; 2006. [http://www.dh.gov.uk/en/ Publicationsandstatistics/Publications/PublicationsPolicyAndGuidance/ DH_4127127]

4. Institute of Medicine: Initial National Priorities for Comparative Effectiveness Research. Washington, DC: National Academy Press; 2009. [http://www.nap. edu/catalog.php?record_id=12648]

5. van Ruler O, Mahler CW, Boer KR, Reuland EA, Gooszen HG, Opmeer BC, de Graaf PW, Lamme B, Gerhards MF, Steller EP, van Till JW, de Borgie CJ, Gouma DJ, Reitsma JB, Boermeester MA; Dutch Peritonitis Study Group: Comparison of on-demand vs planned relaparotomy strategy in patients with severe peritonitis: a randomized trial. JAMA 2007, 298:865-872.

6. Shortell SM: Bending the cost curve: a critical component of health care reform. JAMA 2009, 302:1223-1224.

doi:10.1186/cc9045

Cite this article as: Ghaferi AA: Bending the cost curve in the United States: the role of comparative effectiveness research. Critical Care 2010, 14:168. 